\title{
Haemodynamic Effects and Complications of Unilateral Spinal versus Standard Spinal Anesthesia in Elderly with Low Ejection Fraction Undergone Lower-Limb Surgery
}

\author{
Md. Mushfiqur Rahman'1, Md. Mahbubul Hasan Munir², Raihanuddin³ ${ }^{3}$ Shafiul Alam shaheen ${ }^{4}$, \\ Md. Abdus Salam Khan ${ }^{5}$, Kawsar Sardar ${ }^{6}$, AKM Nurnobi Chowdhury ${ }^{7}$
}

\begin{abstract}
Background: Cardiovascular system may be profoundly affected by spinal anaesthesia due to unavoidable sympathetic blockade which is more prominent in elderly.A restricted sympathetic block during spinal anesthesia may minimize hemodynamic changes. Objective: To assess whether a unilateral spinal anaesthesia using 0.5\% hyperbaric bupivacaine will restrict the sympathetic block to avoid the undesired cardio vascular effects. Materials and method: In this prospective study 60 ASA Ill and IV patients aged between 60-90 years undergoing unilateral lower limb surgery were included. Patients were divided into two groups. In group-A, dural puncture was performed with the patient in the lateral decubitus position with $1.5 \mathrm{~mL}$ of hyperbaric bupivacaine. In group-B, it was performed with the patient in a seated position using $1.5 \mathrm{~mL}$ hyperbaric bupivacaine. Each patient was then placed in supine position. The speed of injection was $1 \mathrm{~mL} / 30 \mathrm{~s}$. Patients were placed in the lateral position with operated side down and kept in this position for 10 minutes. Motor and sensory levels were assessed, and haemodynamic alterations were monitored just after block, 5, 10, 15 and 30 minutes of spinal anaesthesia. Results: The demographic data were found similar in both groups. The time to the onset of the sensory and motor block was significantly shorter in group-B. The duration of motor and sensory block was significantly shorter in group-A. Haemodynamically all the parameters revealed better out come in unilateral spinal anesthesia. The incidence of complications (nausea, headache, and hypotension) was also lower in group A. Conclusion: When unilateral spinal anesthesia was performed using a low-dose, low-volume and low-flow injection technique, it provides adequate sensory-motor block and helps to achieve stable hemodynamic parameters during surgery on a lower limb. Furthermore, this technique avoids unnecessary paralysis on the non-operated side.
\end{abstract}

Keywords: Unilateral spinal anaesthesia; haemodynamic changes.

Delta Med Col J. Jan 2017;5(1):20 - 24

\section{Introduction}

Cardiovascular system may be profoundly sympathetic blockade which is more prominent in affected by spinal anaesthesia due to unavoidable elderly. Numerous studies have been conducted to

1. Junior Consultant, Dept. of Anaesthesia, Analgesia \& Surgical-ICU, BIRDEM General Hospital, Shahbagh, Dhaka, Bangladesh.

2. Associate professor, Dept. of Anaesthesia, Analgesia \& Surgical-ICU, BIRDEM General Hospital, Shahbagh, Dhaka, Bangladesh.

3. Assistant professor, Dept. of Anaesthesia, Analgesia \& Surgical-ICU, BIRDEM General Hospital, Shahbagh, Dhaka, Bangladesh.

4. Registrar, Dept. of Anaesthesia, Analgesia \& Surgical-ICU, BIRDEM General Hospital, Shahbagh, Dhaka, Bangladesh.

5. Professor, Dept. of Anaesthesia, Analgesia \& Surgical-ICU, BIRDEM General Hospital, Shahbagh, Dhaka, Bangladesh.

6. Associate professor, Dept. of Anaesthesia, Analgesia \& Surgical-ICU, BIRDEM General Hospital, Shahbagh, Dhaka, Bangladesh.

7. Professor \& Head, Dept. of Anaesthesia, Analgesia \& Surgical-ICU, BIRDEM General Hospital, Shahbagh, Dhaka, Bangladesh.

Correspondence: Dr. Md.Mushfiqur Rahman. e-mail: rahmaanmushfique@gmail.com 
see the cardiovascular effects of spinal blockade. Hypotension is the most frequent side effect of spinal anaesthesia, occurring in more than $30 \%$ of patients. ${ }^{1}$

Ward et al. ${ }^{2}$ reported a decrease in mean arterial blood pressure of $21.3 \%$ of the base line following spinal anaesthesia. He also reported that a level of spinal anaesthesia to $\mathrm{T} 5$ resulted in an increase in heart rate by $3.7 \%$. The cardio accelerator fibres originate from T1-T4, so the level of spinal anaesthesia affecting these dermatomes may cause bradycardia. The unilateral spinal anaesthesia has been claimed by many as an alternative technique, to restrict the undesired sympathetic block. ${ }^{3}$ There are many benefits to this technique including fewer hemodynamic changes, less urinary retention, more satisfied patients, better motility during recovery and the restriction of selective nerve block to the relevant limb.

This study was undertaken to evaluate whether unilateralspinal anesthesia can avoid the undesired cardiovascular effects and patient satisfactions accompanying the conventional spinal anaesthesia in elderly cardiac compromised patient.

\section{Materials and method}

This prospective study included sixty adult patients scheduled for unilateral lower limb surgery.

The patients were divided in two randomized groups: A and B. In group-A, unilateral spinal anesthesia was used with $7.5 \mathrm{mg}$ of $0.5 \%$ hyperbaric bupivacaine. In group-B, standard spinal anesthesia was used with $7.5 \mathrm{mg}$ of $0.5 \%$ hyperbaric bupivacaine. Patient age ranged from 60 to 85 years. The patients were in ASA class III or IV. The duration of Nil per os (NPO) time and the sedation regimen were the same in both groups. Patients with any absolute contraindication for regional anesthesia were excluded from the study.
Ethical approval for this study was provided by Hospital Ethics Committee, BIRDEM General Hospital, Shahbagh, Dhaka. Informed consent was obtained from each patient to ensure that he or she understood that the technique used for spinal anesthesia would be modified. An IV cannula was inserted, and then a $10 \mathrm{~mL} / \mathrm{kg}$ intravenous infusion of lactate Ringer's solution was administered over 20 min. All patients underwent standard monitoring, including electrocardiography, non-invasive blood pressure measurements and pulse oximetry.

In group-A, spinal anesthesia was performed with the patient in the sitting position at the L3-L4 inter space using a 25-G Quincke spinal needle in sterile condition. Once intrathecal placement had been confirmed, $7.5 \mathrm{mg}$ of hyperbaric bupivacaine $0.5 \%$ was injected. The patient was then placed in the supine position.

In group-A, the patients were placed in the lateral decubitus position with the operating limb in the lower position. Similar to the technique used for group-A, the L3-L4 inter-vertebral space was detected, and then spinal anesthesia was performed with a 25-G Quincke spinal needle. After the confirmation of intrathecal needle placement, $7.5 \mathrm{mg}$ of hyperbaric bupivacaine $0.5 \%$ was injected at a speed of $5 \mathrm{mg}$ every $30 \mathrm{~s}$. The patient was kept in this position for 10 minutes. After confirming a unilateral sensory block up to T10 dermatome, surgery was allowed to proceed.

In group-B, spinal anesthesia was performed with the patient in the sitting position at the L3-L4 inter space using a 25-G Quincke spinal needle in sterile condition. Once intrathecal placement had been confirmed, $7.5 \mathrm{mg}$ of hyperbaric bupivacaine $0.5 \%$ was injected. The patient was then placed in the supine position. To reduce patient anxiety, 2 mg of midazolam was injected IV.

Sensory block was assessed by using ice packs, bilaterally, at every 5 minutes, for 30 minutes after 
spinal anaesthesia. Motor block of lower limbs was also assessed bilaterally using Bromage scale at baseline and at every five minutes, for 30 minutes after spinal anesthesia.

The Bromage scale was, $0=$ no paralysis; $1=$ inability to raise extended leg; $2=$ inability to raise flex knee; $3=$ inability to do dorsi flexion of foot but can wiggle toes and $4=$ inability to move at all. The patient was asked to raise the extended leg, flex the knee, flex the ankle and was rated from 0 - 4. The haemodynamic variables such as blood pressure and heart rate were monitored before spinal anesthesia, just after spinal anaesthesia and then every 5 minutes interval for 30 minutes. If systolic blood pressure decrease by more than $30 \%$ of base line or systolic blood pressure less than $90 \mathrm{mmHg}$, ephedrine $5 \mathrm{mg}$ in incremental doses with maximum of $50 \mathrm{mg}$ was used. Bradycardia, was defined as heart rate less than 50 beats/minute and was treated with atropine 0.5-1 mg given intravenously.

The duration of surgery and any complications regarding anaesthesia were also recorded. All patients were shifted to recovery room after surgery. Patients were discharged from recovery room when they were able to move both legs and their haemodynamic status was stable.

The clinical data including the onset of sensory and motor block, hemodynamic changes, duration of sensory and motor block and the complications of spinal anesthesia were evaluated using SPSS version 19.6 for windows. Unpaired t-test, chi-square and Fisher's exact test were used where applicable. $p$ value of $<0.05$ was considered as significant.

\section{Results}

Demographic data of patients are shown in Table I. No demographic variables differed significantly between Group-A and Group-B.
Table I: Demography

\begin{tabular}{lccc}
\hline Parameters & $\begin{array}{c}\text { Group-A } \\
(\mathbf{n}=\mathbf{3 0})\end{array}$ & $\begin{array}{c}\text { Group-B } \\
(\mathbf{n}=\mathbf{3 0})\end{array}$ & p value \\
\hline Age in year(Mean+SD) & $62.33 \pm 6.05$ & $60.93 \pm 4.06$ & 0.290 \\
Weight in Kg (Mean+SD) & $58.20 \pm 4.22$ & $59.46 \pm 3.25$ & 0.226 \\
Height in cm (Mean+SD) & $165.30 \pm 3.44$ & $166.13 \pm 4.94$ & 0.270 \\
ASA physical status III & $5(16.66 \%)$ & $6(20 \%)$ & 0.629 \\
ASA physical status IV & $25(83.33 \%)$ & $24(80 \%)$ & 0.498 \\
\hline
\end{tabular}

Intra-operative period pulse rate was slower at each time interval in Group-B in comparison with Group-A. In Group-A mean pulse rate ranged from $79 \pm 6.2$ beats/min to $69 \pm 2.2$ beats $/ \mathrm{min}$ while it ranged between $76 \pm 6.5$ (beats $/ \mathrm{min}$ ) to $68 \pm 7.4$ (beats/min) in Group B. Significant decrease in group-B was observed at 15 and 30 minutes after block (Table II).

Table II: Comparison of heart rate between groups

\begin{tabular}{lccc}
\hline Heart rate (beats/min) & $\begin{array}{c}\text { Group-A } \\
(\mathbf{n}=\mathbf{3 0})\end{array}$ & $\begin{array}{c}\text { Group-B } \\
(\mathbf{n}=\mathbf{3 0})\end{array}$ & p value \\
\hline Before block & $78 \pm 4.5$ & $76 \pm 6.5$ & 0.256 \\
Just after block & $73 \pm 9.2$ & $74 \pm 10.8$ & 0.092 \\
5 minutes after block & $69 \pm 2.2$ & $73 \pm 7.24$ & 0.053 \\
10 minutes after block & $78 \pm 5.24$ & $73 \pm 7.34$ & 0.067 \\
15 minutes after block & $75 \pm 5.45$ & $73 \pm 6.20$ & 0.049 \\
30 minutes after block & $79 \pm 6.2$ & $68 \pm 0.4$ & 0.042 \\
Immediate post operative & $78 \pm 4.43$ & $70 \pm 5.67$ & 0.055 \\
period & & & \\
\hline
\end{tabular}

Table III shows the status of systolic and diastolic blood pressure in two groups. The mean change of systolic blood pressure varies in Group-B from $142.36+12.89 \mathrm{mmHg}$ to $100.6 \pm 10.8 \mathrm{mmHg}$ and in Group-A from $140.83+12.25 \mathrm{mmHg}$ to $120.40+8.82 \mathrm{mmHg}$. The mean change of diastolic blood pressure varies in Group-B from $79.6 \pm 4.1 \mathrm{mmHg}$ to $70.8 \pm 1.8 \mathrm{mmHg}$ and in Group-A $80.1 \pm 4.5 \mathrm{mmHg}$ to $75.8 \pm 6.8 \mathrm{mmHg}$. Both mean diastolic and systolic blood pressure significantly decreased in group-B in comparison to group-A at 5, 10, 15 and 30 minutes after block. 
Table III: Comparison of blood pressure between groups

\begin{tabular}{lccc}
\hline Blood Pressure (mmHg) & $\begin{array}{c}\text { Group-A } \\
(\mathbf{n}=\mathbf{3 0})\end{array}$ & $\begin{array}{c}\text { Group-B } \\
(\mathbf{n}=\mathbf{3 0})\end{array}$ & p value \\
\hline Systolic & & & \\
Before block & $140.83 \pm 12.25$ & $142.36 \pm 12.89$ & 0.243 \\
Just after block & $133.3 \pm 6.3$ & $134.0 \pm 10.1$ & 0.067 \\
5 minutes after block & $130.6 \pm 5.1$ & $111.1 \pm 10.5$ & 0.043 \\
10 minutes after block & $127.5 \pm 4.8$ & $106.6 \pm 13.9$ & 0.048 \\
15 minutes after block & $120.40 \pm 8.82$ & $100.6 \pm 10.8$ & 0.047 \\
30 minutes after block & $127.5 \pm 3.8$ & $108.3 \pm 6.9$ & 0.043 \\
Immediate post operative period & $127.6 \pm 4.0$ & $108.3 \pm 10.8$ & 0.076 \\
Diastolic & & & \\
Before block & $80.1 \pm 4.5$ & $79.6 \pm 4.1$ & 0.243 \\
Just after block & $79.1 \pm 3.4$ & $75.1 \pm 7.4$ & 0.094 \\
5 minutes after block & $78.3 \pm 4.7$ & $72.8 \pm 2.5$ & 0.049 \\
10 minutes after block & $76.3 \pm 5.4$ & $72.3 \pm 3.5$ & 0.042 \\
15 minutes after block & $75.8 \pm 6.8$ & $70.8 \pm 1.8$ & 0.033 \\
30 minutes after block & $79.1 \pm 1.8$ & $71.1 \pm 2.1$ & 0.041 \\
Immediate post operative period & $79.1 \pm 1.8$ & $75.3 \pm 5.1$ & 0.087 \\
\hline
\end{tabular}

The change of mean arterial pressure varies in Group-B from Group-A. Significant changes were observed in three occasions (5 minutes, 10 minutes and 15 minutes after block) (Table V).

Table V: Comparison of mean arterial pressure between groups

\begin{tabular}{lccc}
\hline Occasions & $\begin{array}{c}\text { Group-A } \\
(\mathbf{n = 3 0 )}\end{array}$ & $\begin{array}{c}\text { Group-B } \\
(\mathbf{n = 3 0 )}\end{array}$ & p value \\
\hline Before block & $95.6 \pm 3.1$ & $94.0 \pm 2.1$ & 0.231 \\
Just after block & $94.3 \pm 3.6$ & $89.6 \pm 5.5$ & 0.098 \\
5 minutes after block & $94.5 \pm 3.8$ & $85.0 \pm 6.5$ & 0.049 \\
10 minutes after block & $93.8 \pm 3.1$ & $82.8 \pm 4.3$ & 0.047 \\
15 minutes after block & $89.8 \pm 3.9$ & $81.0 \pm 4.6$ & 0.034 \\
30 minutes after block & $93.0 \pm 2.5$ & $84.1 \pm 1.9$ & 0.037 \\
Immediate post operative & $93.0 \pm 3.1$ & $82.5 \pm 3.5$ & 0.075 \\
period & & & \\
\hline
\end{tabular}

Table VI shows the distribution of complications between the groups where no complication developed in Group-A.

Table VI: Distribution of complications between groups

\begin{tabular}{lcc}
\hline Complications & $\begin{array}{c}\text { Group-A } \\
(\mathbf{n}=\mathbf{3 0})\end{array}$ & $\begin{array}{c}\text { Group-B } \\
(\mathbf{n}=\mathbf{3 0})\end{array}$ \\
\hline Hypotension & 0 & 6 \\
Bradycardia & 0 & 5 \\
Nausea andvomiting & 0 & 8 \\
Headache & 0 & 8 \\
\hline
\end{tabular}

Better outcome was observed regarding duration and quality of anaesthesia where Group-A showed better outcome (Table VII).

Table VII: Duration and quality of block

\begin{tabular}{lccc}
\hline Parameters & Group A & GroupB & p-value \\
\hline $\begin{array}{l}\text { Duration of } \\
\text { motor block (min) }\end{array}$ & $36.65 \pm 32.38$ & $174.11 \pm 17.42$ & 0.02 \\
$\begin{array}{l}\text { Duration of } \\
\text { sensory block (min) }\end{array}$ & $157.12 \pm 17.07$ & $189.40 \pm 21.15$ & 0.00 \\
Bromage scale IV & 13 cases & 8 cases & \\
Bromage scale III & 23 cases & 28 cases & $0.059 \#$ \\
\hline
\end{tabular}

\section{Discussion}

The patient's position during and immediately after spinal anesthesia influences the spinal distribution of drugs. If an anesthetic drug solution is hyperbaric with respective the cerebrospinal fluid, it is possible to create a unilateral block. Moreover, the distance between the left and right nerve roots in the lumbar and thoracic region is about 10-15 cm, which makes it possible to achieve unilateral spinal anesthesia. ${ }^{4}$ Kusniemi et al. reported that hyperbaric bupivacaine is more effective in achieving unilateral spinal anesthesia than plain bupivacaine. ${ }^{5}$ However, determining the optimal time for lateral positioning is difficult when a high dose of hyperbaric bupivacaine $(12-20 \mathrm{mg})$ is used. The anesthetic drug may migrate even when the patient is placed in the lateral position for 30-60 min. Conversely, if a low dose $(5-8 \mathrm{mg})$ of anesthetic solution is used, putting the patient in the lateral position for 10-15 min may prevent migration of the anesthetic drug. In this study, we injected $1.5 \mathrm{ml}(7.5 \mathrm{mg})$ of hyperbaric bupivacaine $0.5 \%$ to achieve unilateral spinal anesthesia. The patient was kept in the lateral position for $10 \mathrm{~min}$, which led to unilateral spinal anesthesia in $94.45 \%$ of cases. In two cases, the anesthetic drug spread to the other side, resulting in bilateral spinal anesthesia. In a study 
performed by Esmaoglu, the patient was in the lateral position for $05 \mathrm{~min}$. This approach yielded an $85.7 \%$ success rate. This discrepancy in terms of the success rate seems to be dependent on the duration of time spent in the lateral position. ${ }^{6}$ Notably, none of the patients in the unilateral spinal anesthesia group experienced hypotension, but six patients in the bilateral group had hypotension and were treated by IV ephedrine. Chohan and Afshan administered unilateral spinal anesthesia prior to lower-limb surgery in elderly patients with ASA classificationof III or IV (average age, 60). The authors found no significant hemodynamic changes. They used hyperbaric bupivacaine $0.5 \%$ (1.1-1.2 mL). ${ }^{7} \mathrm{In}$ our study, there was no bradycardia in the unilateral group, but in the bilateral group, 5 patients had bradycardia. On average, the time to the onset of anesthesia and immobility was faster in the bilateral as compared to the unilateral spinal anesthesia group. The sensory and motor block lasted for less time in the unilateral as compared to the bilateral group. Unilateral spinal anesthesia is therefore suitable for outpatient surgery. Valanne used 4 or $6 \mathrm{mg}$ of bupivacaine to induce unilateral spinal anesthesia in 106 patients scheduled to undergo knee arthroscopy. While both doses were sufficient for sensory and motor block, $4 \mathrm{mg}$ of bupivacaine achieves a more rapid regression of motor function. 8

\section{Conclusion}

Unilateral spinal anesthesia with a low dose (7.5 $\mathrm{mg})$ limited volume $(1.5 \mathrm{~mL})$ induces sufficient sensory and motor block with anappropriate level of analgesia for lowerlimb surgery. This technique is a good alternative of conventional spinal and achieves stable hemodynamics, particularly in elderlyASA classIII/IV and patients with low ejection function.

\section{References}

1. Carpenter RL, Caplan RA, Brown DL, Stephenson $\mathrm{C}, \mathrm{Wu} \mathrm{R}$. Incidence and Risk Factor for Side Effect Of spinal Anesthesia. Anesthesiology. 1992;76(6): 906-16.

2. Ward RJ, Bonica JJ, Frend PG, Akamatsu T, Danziger F, Englesson S. Epidural and Subarachnoid Anesthesia. Cardiovascular and Respiratory Effects. JAMA. 1965;191(4):275-78.

3. Casati A, Fanelli G, Beccaria P, Aldegheri G, Berti M, Senatore R, et al. Block Distribution and Cardiovascular Effects of Unilateral Spinal Anesthesia by $0.5 \%$ Hyperbaric Bupivacaine. A Clinical Comparison with Bilateral Spinal Block. Minerva Anesthesiol. 1998;64:307-12,

4. Imbelloni LE, Beato L, Cordeiro JA. Unilateral Spinal Anesthesia with Low $0.5 \%$ Hyperbaric Bupivacaine Dose. Anestesiology. 2004;5:4-11

5. Kuusniemi KS, Pihlajamaki KK, Pitkanen MT. A Low Dose of Plain or Hyperbaric Bupivacaine for Unilateral Spinal Anesthesia. Reg Anesth Pain Med. 2000;25(6):5-10.

6. Esmaoglu A, Boyaci A, Ersoy O, Güler G, Talo R, Tercan E. Unilateral Spinal Anesthesia with Hyperbaric Bupivacaine. Acta Anaesthesiol Scand. 1998;42(9):1083-87.

7. Chohan U, Afshan G, Hoda MQ. Hemodynamic Effects of Unilateral Spinal Anesthesia in High Risk Patients. J Pak Med Assoc. 2002:52-66.

8. Valanne JV, KorhoneuAM, Jokela RM, Ravaska P, Korttila KK. Selective Spinal Anesthesia: A Comparison of Hyperbaric Bupivacaine $4 \mathrm{mg}$ versus $6 \mathrm{mg}$ for Outpatient Knee Arthroscopy. Anesth Analg. 2001;93(6):1377-79. 